\title{
Chronic symptoms persisting after travel-related infections
}

\author{
Anna Kuna ${ }^{1}$, Michał Gajewski ${ }^{2}$ \\ ${ }^{1}$ Department of Tropical and Parasitic Diseases, Institute of Maritime and Tropical Medicine, Gdynia, \\ Faculty of Health Sciences, Medical University of Gdansk, Poland \\ ${ }^{2}$ Outpatient Clinic of Hepatology, Voivodship Hospital, Szczecin, Poland
}

\begin{abstract}
The authors present the current state of knowledge about the long term sequelae of the common travel-related infections associated with immunological dysregulation. Travellers' diarrhoea, chikungunya and dengue are common in travellers and protracted manifestations such as post-infectious irritable bowel syndrome (travellers' diarrhoea), arthritis (chikungunya) or post-dengue syndrome may be more prevalent than previously thought. Attention should be paid to active prevention of the infections during travel, especially when an effective treatment against long-term sequelae has not been established. Further studies should be designed in order to determine the interactions between the host, the environment and the pathogens, as well as to identify the prognostic factors for developing long-term manifestations after infections in a large group of travellers.
\end{abstract}

(Int Marit Health 2018; 69, 3: 207-212)

\section{Key words: travel-related disease, communicable diseases, long-term complications}

\section{TRAVELLERS' DIARRHOEA}

\section{DEFINITION, EPIDEMIOLOGY, CLINICAL SYMPTOMS}

Travellers' diarrhoea (TD) is one of the most common travel-associated diseases. Virtually everyone experienced diarrhoea at least once in their lifetime, in particular while travelling through developing countries. Acute TD has been defined as passage of $\geq 3$ unformed stools within a 24-hour period. The signs of enteric infection may include abdominal pain, nausea, vomiting, cramping, flatulence, fever, stool urgency, bloody or mucous stool, or tenesmus [1].

The risk of TD depends mostly on the destination; the highest risk prevails in Asia, the Middle East, Africa, Central and South America [2]. The majority of the individuals who develop acute diarrhoea will have self-limiting symptoms lasting $<5$ days, even without any treatment. Unfortunately, a portion of the patients will develop prolonged symptoms lasting for years [3].

\section{LONG-TERM SEQUELAE OF THE TRAVELLERS' DIARRHOEA}

Over 55 years ago, Chaudhary and Truelove [4] presented a series of 130 irritable bowel syndrome (IBS) cases and demonstrated that $26 \%$ of these patients associated the onset of IBS with an episode of dysentery [5]. Numerous studies conducted since then confirmed that, depending on the study, approximately $4 \%$ up to even $36 \%$ of IBS cases develop after a bout of infectious diarrhoea. In such event, the disease is considered post-infectious IBS (PI-IBS). The duration of the symptoms may vary and may even exceed 12 years [6]. PI-IBS appears to be caused by a non-specific response to a prior infection which may have been caused by a variety of enteric pathogens, including Campylobacter spp., Salmonella spp., and diarrhoeagenic strains of Escherichia coli including ETEC, Shigella spp., Cryptosporidium spp. or Giardia spp. [7-11].

Given the total number of travellers and the frequency of diarrhoea while traveling, the global population of patients suffering from PI-IBS may be significant. Irritable 
bowel syndrome is one of the most common functional gastrointestinal disorders in the world [12], causing illness in $10-15 \%$ of the western populations [6, 13]. PI-IBS is diagnosed according to the Rome IV criteria, with the additional criterion of onset following an acute infectious gastroenteritis characterised by two or more symptoms such as fever, vomiting, diarrhoea, and a positive stool culture result $[14,15]$. Therefore, PI-IBS and IBS have similar clinical features, but the former is more likely to occur in the persons who travel [6].

The risk factors for developing PI-IBS include genetic, physical, psychosocial and bacterial factors. One of the strongest predictors is the duration and severity of the initial infection $[16,17]$. Compared to the patients with diarrhoea lasting shorter than one week, subjects with symptoms lasting $>3$ weeks have been determined to have an 11 -fold increase in the risk of developing PI-IBS [16]. Younger age and age-related more adventurous dietary habits, pre-existing psychological disorders such as anxiety, major depression, sleep disorders, hypochondriasis, adverse life events in the preceding months, tobacco smoking, elevated body mass index, alcohol abuse, and stress, are among the suspected or established PI-IBS risk factors [5, 6, 16, 18-23].

Some of the researchers have suggested an association between the type or species of the infecting pathogen and the risk of developing PI-IBS but others have found no such relation $[16,24]$. The most highly suspected species include the LT-producing ETEC, Providencia spp. [18], Campylobacter spp. [25], Salmonella spp. [26] and Shigella spp. $[7,24]$. In the majority of TD cases it is difficult, however, to determine the responsible pathogen, as many of the cases occur where the traveling patient has no ready access to medical care or a medical laboratory.

Further risk factors include inflammation, serotonin production, mast cells activation, cytokine-mediated response, changes in the enteric nerves and altered microbiome in the digestive tract [19]. Patients with PI-IBS probably also have persistent mucosal immunologic dysregulation with altered intestinal permeability and motility which can lead to chronic intestinal symptoms [5]. They also appear to have higher intraepithelial lymphocyte and the lamina propria lymphocyte counts [8]; also, increased numbers of mucosa mast cells have been found in many PI-IBS as well as IBS-D patients [7, 27, 28]. The release of the mediators from mast cells probably contributes to the visceral hypersensitivity by activating the enteric afferent nerves [29, 30]. Among the cytokines, interleukin-1 beta is a crucial pro-inflammatory factor, and its concentration has been demonstrated to be increased in the terminal ileum and the recto-sigmoid colon of the PI-IBS patients [7] as well as in rectal biopsies of the patients who had PI-IBS [9]. Interleukin- 6 is increased in both the IBS and depressed patients, showing the interesting correlation between psychological and infectious factors [31].

Before the recognition of PI-IBS, the main concern in the management of travellers' diarrhoea was the alleviation of clinical symptoms to prevent inconvenience and complications while travelling [6]. It is very important to ensure that patients understand the mechanism of PI-IBS and that although they are to improve, the symptoms may be prolonged and recur even for some years [19]. Patients with abdominal pain and anxiety may be offered mild anxiolytics [19]. The symptoms of diarrhoea and stool urgency respond well to loperamide [19].

The increasing understanding of the mechanism and pathophysiology of PI-IBS allows the researchers to attempt novel treatment options such as prednisolone [32], ketotifen (a mast cell stabilizer), mesalazine, alosetron, ramosetron or ondansetron [19]. In general, the treatment of PI-IBS is similar to that of non-PI-IBS. In 2005, Hungin et al. [33] reported that only $14 \%$ of the patients with IBS were completely satisfied with the effects of their therapy. Therefore, it should be emphasized that every effort must be made to prevent the disease where possible [5].

\section{CHIKUNGUNYA}

\section{DEFINITION, EPIDEMIOLOGY, CLINICAL SYMPTOMS}

Chikungunya virus (CHIKV) infection is caused by an arbovirus of the Alphavirus genus transmitted to humans by the Aedes mosquitos. Outbreaks have been recorded in Africa, Europe, Asia, as well as in the regions of the Pacific and Indian Oceans. In 2013, CHIKV was registered in the Americas for the first time [2]. During the acute stage of the disease, the patients develop fever, arthralgia, joint stiffness and joint swelling. Infection has usually an uncomplicated course, but a prolonged and frustrating arthralgia persists in a significant fraction of the patients, sometimes for years.

\section{LONG-TERM SEQUELAE OF CHIKUNGUNYA}

Arthralgia is one of the typical symptoms in CHIKV infected patients. Unfortunately, the pain does not always pass once the acute stage of the infection, but it can last for months or even years. Depending on the research source, the symptoms continue in $32 \%$ to $70 \%$ of patients [34-37]. The time of the follow-up was between 4 months and 6 years [34].

In 1984, Brighton and Simson [38] described the post-chikungunya destructive polyarthritis in South Africa. The next step in understanding this phenomenon was taken during the outbreaks on the Reunion Island and in India. As many as $17 \%$ to $84 \%$ patients reported long-lasting pain, disability, muscle pain, impaired quality of life and the need for extensive treatment [34]. The spectrum of post-chikungunya symptoms also includes tendinitis, tenosynovitis, plantar 
fasciitis, carpal tunnel syndrome, polyarthralgia, rheumatoid arthritis, and psoriatic arthritis [39-41]. The duration of symptoms may exceed 33 months. In case of relapse, the pain is often observed in the same locations [34].

Among the risk factors associated with post-chikungunya polyarthritis, older age is one of the more frequently reported [34]. The duration of the initial acute stage of the disease is also important: during an outbreak on the Reunion Island, $17 \%$ of the patients in whom the acute stage was $\leq 14$ days suffered from chronic symptoms and if the stage was $>14$ days, chronic symptoms were seen in $84 \%$ of the patients [36, 42].

The comorbidities were reported by many patients, in some studies by as many as $60 \%$, they included degenerative disc disease (52\%), arthritis (34\%) and depression (23\%) [34].

The probable mechanism of persistent symptoms is the activation of the immune system by the viral load in the acute stage of the CHIKV infection. It triggers the production of interferons, and monocytes and macrophages are the main target cells for CHIKV. Examination of biopsy specimens detected that CHIKV can hide in tissues and provoke tissue damage [43].

Post-chikungunya treatment should be initiated with analgesics, physiotherapy and local therapy. Other treatment methods may also be considered, e.g. a short-course of corticosteroids or nonsteroidal anti-inflammatory drugs. Disease-modifying anti-rheumatic drugs have been documented to control the inflammatory process and to prevent bone erosions. If the resistance to or dependence on corticosteroids is observed, the probability of chronic post-infection inflammatory rheumatism is high [44]. Probable resistance to or dependence on corticosteroids beyond the third month after the disease onset is highly evocative of post-chikungunya chronic inflammatory rheumatism. This finding suggests early treatment with disease-modifying anti-rheumatic drugs to control the inflammatory process, to prevent bone erosions, and to prevent the inevitable side effects of prolonged corticoid therapy [44]. In some patients, tricyclic antidepressants, tramadol and antiepileptic drugs may be considered, especially in neuropathic pain [45].

Because the effect of the treatment is uncertain, the patient should be made aware of the mechanism of the disease; this could help them accept the disease and facilitate the recovery.

\section{DENGUE}

\section{DEFINITION, EPIDEMIOLOGY, CLINICAL SYMPTOMS}

Dengue is a viral disease transmitted by the Aedes mosquitos. Dengue virus (DENV) infection is endemic in the tropical and subtropical countries. During the last decades it has emerged as a serious international public health threat as almost half of the world's population are now at risk of infection, including European basin of the Mediterranean Sea (Croatia, France) [46]. Any of the five serotypes (DENV-1-DENV-5) of the dengue virus can produce a plethora of symptoms, ranging from an asymptomatic infection to a severe, life-threatening disease.

Dengue is characterised by high fever, chills, severe headache, skin rash and fatigue. The disease is usually benign and self-limiting, but complications may occur, with mortality rate approaching $5 \%$. In the recent years, persisting post-dengue symptoms have been described.

\section{LONG-TERM SEQUELAE OF DENGUE}

A persistent and incapacitating post-infectious fatigue syndrome might be associated with a number of infectious diseases, such as mononucleosis, Lyme disease, $\mathrm{Q}$ fever or Epstein-Barr virus infection but also with dengue. Following the acute phase of the illness, patients may suffer from long-term fatigue manifestations. They describe these symptoms as a sense of chronic exhaustion that decreases their capacity for physical and mental work [47].

Depending on the study, $25 \%$ to $50 \%$ of the patients report post-dengue symptoms $[47,48]$. No clinical signs were observed in the group of asymptomatic dengue infection with only a serologic proof of the infection. The time of duration of post-dengue symptoms was up to 2 years. The clinical manifestations reported by the patients through the time of observation for 2 years after the acute phase of dengue infection included hand weakness, muscle pain, asthenia, arthralgia, general malaise, retroocular pain, arthropathy, irritability, palpitations, memory impairment, headache, vomiting, nausea, dizziness, anorexia, alopecia, rash, vaginal bleeding, diarrhoea, gingivorrhagia. The majority of the analysed patients had a history of more than one previous dengue infections [48].

There are a number of risk factors which can be attributed to the presence of long-term post-dengue sequelae. The majority of them are associated with the immunological dysregulation. One of the studies identified sex as a risk factor, with clinical manifestations being more persistent in women than in men (96.7\% vs $36.7 \%$ ) [48]. In another study, female sex, advanced age, the presence of chills, and the absence of rash were associated with the post-dengue fatigue symptom. There was no significant correlation between dengue severity and fatigue [47]. As stated above, dengue infection without clinical manifestations, diagnosed based on the serological tests results only, was not associated with clinical sequelae. It suggests that the infection per se is not a trigger for the immunological dysregulation. 
The phenomenon of antibody-enhancement has been well described in the pathogenesis of dengue virus infection. Non-neutralizing antibodies circulating in the serum of the patients enhance viral entry through the Fc receptor and worsen the course of infection [49]. An increased expression of Fc activating receptors on the monocytes and macrophages is associated with an increase in the production of inflammatory cytokines [50]. The following autoimmune markers were assessed in a subset of asymptomatic individuals: complement factors $\mathrm{C} 3 / \mathrm{C} 4$, rheumatoid factor (RF), C-reactive protein (CRP), antinuclear antibodies (ANA), and immune complexes (IC). Persistent clinical manifestations were also associated with high IgG titres. On the other hand, the predominant neurological clinical symptoms such as joint, muscle or bone pain showed no statistically important correlation with the IgG titres [48]. In some patients with persistent post-dengue symptoms, an increased level of CRP was detected. It may suggest a non-degenerative, immune-mediated process that further enhances the damage. It can be a result of the presence of interleukin- 6 or interleukin-1, interferon $\alpha, \beta$ and $\gamma$, and tumour necrosis factor [51], possibly released as a result of the persistent activation of Fc-gamma-RIla on the neutrophils, macrophages, and dendritic cells [52]. An overproduction of cytokines such as C3a and C5a results in an immune-mediated damage to the endothelial cells [47]. Seventy-six per cent of the individuals with persistent post-dengue clinical symptoms showed alterations in the immunological markers such as C3 and C4 complement factors, RF, ANA, IC, and CRP [48].

No effective treatment method of post-dengue syndrome has yet been developed.

Dengue may also cause permanent neurological or ocular damage, including stroke [53, 54], parkinsonism [55], myelitis [56], AQP4-antibody-related neuromyelitis optica spectrum disorder [57, 58], necrotising scleritis [59], dengue-associated maculopathy [60], outer retinal damage [61], or glaucoma [62].

\section{CONCLUSIONS}

Genetic and environmental factors such as acute viral or bacterial infection may induce transient autoimmune responses. Travellers' diarrhoea, chikungunya and dengue infection are common in travellers and their post-infectious manifestations may be more prevalent than previously thought. There are many patients with a history of travel who report clinical symptoms and a significant percentage of those-patients may have acquired an infection while travelling. They seek diagnosis, but an active infection is almost never detected, and thus effective therapeutic options are limited.

Attention should be paid to active prevention measures during travel, especially when an effective treatment against long-term sequelae has not been established. Physicians and public health authorities should also be prepared to deal with and manage patients with post-infectious manifestations not only in the epidemic areas, but also in the group of returning travellers.

Further studies should be designed in order to determine the interactions between the host, the environment and the pathogens, as well as to identify the prognostic factors for developing long-term manifestations after infections in a larger population of travellers. It is yet to be determined whether intensive and early treatment of tropical infections would minimise the occurrence the post-infectious symptoms.

\section{CONFLICT OF INTEREST STATEMENT}

The authors declare no conflict of interest.

\section{REFERENCES}

1. DuPont HL, Ericsson CD. Prevention and treatment of traveler's diarrhea. N Engl J Med. 1993; 328(25): 1821-1827, doi:10.1056/ NEJM199306243282507, indexed in Pubmed: 8502272.

2. CDC CDC. Yellow Book 2018: Health Information for International Travel. Oxford University Press, New York. 2017.

3. Neal KR, Barker L, Spiller RC. Prognosis in post-infective irritable bowel syndrome: a six year follow up study. Gut. 2002; 51(3): 410-413, indexed in Pubmed: 12171965.

4. Chaudhary N, Truelove SC. The irritable colon syndrome. A study of the clinical features, predisposing causes, and prognosis in 130 cases. Q J Med. 1962; 31: 307-322, indexed in Pubmed: 13878459.

5. DuPont AW. Postinfectious irritable bowel syndrome. Clin Infect Dis. 2008; 46(4): 594-599, doi: 10.1086/526774, indexed in Pubmed: 18205536.

6. DuPont HL, Galler G, Garcia-Torres F, et al. Travel and travelers' diarrhea in patients with irritable bowel syndrome. Am J Trop Med Hyg. 2010; 82(2): 301-305, doi: 10.4269/ajtmh.2010.09-0538, indexed in Pubmed: 20134008.

7. Wang LH, Fang XC, Pan GZ. Bacillary dysentery as a causative factor of irritable bowel syndrome and its pathogenesis. Gut. 2004; 53(8): 1096-1101, doi: 10.1136/gut.2003.021154, indexed in Pubmed: 15247174.

8. Spiller RC, Jenkins D, Thornley JP, et al. Increased rectal mucosal enteroendocrine cells, T lymphocytes, and increased gut permeability following acute Campylobacter enteritis and in post-dysenteric irritable bowel syndrome. Gut. 2000; 47(6): 804-811, indexed in Pubmed: 11076879.

9. Gwee KA, Collins SM, Rajnakova A, et al. Increased rectal mucosal expression of interleukin 1 beta in recently acquired post-infectious irritable bowel syndrome. Gut. 2003; 52(4): 523-526, doi: 10.1136/ gut.52.4.523.

10. Stiff RE, Davies AP, Mason BW, et al. Long-term health effects after resolution of acute Cryptosporidium parvum infection: a 1-year follow-up of outbreak-associated cases. J Med Microbiol. 2017; 66(11): 1607-1611, doi: 10.1099/jmm.0.000609, indexed in Pubmed: 28984243.

11. Litleskare S, Rortveit G, Eide GE, et al. Prevalence of Irritable Bowel Syndrome and Chronic Fatigue 10 Years After Giardia Infection. Clin Gastroenterol Hepatol. 2018; 16(7): 1064-1072.e4, doi: 10.1016/j.cgh.2018.01.022, indexed in Pubmed: 29378314. 
12. Drossman DA, Camilleri M, Mayer EA, et al. AGA technical review on irritable bowel syndrome. Gastroenterology. 2002; 123(6): 2108-2131, doi:10.1053/gast.2002.37095, indexed in Pubmed: 12454866.

13. Porter CK, Faix DJ, Shiau D, et al. Postinfectious gastrointestinal disorders following norovirus outbreaks. Clin Infect Dis. 2012; 55(7): 915-922, doi:10.1093/cid/cis576, indexed in Pubmed: 22715178.

14. Dunlop SP, Jenkins D, Spiller RC. Distinctive clinical, psychological, and histological features of postinfective irritable bowel syndrome. Am J Gastroenterol. 2003; 98(7): 1578-1583, doi: 10.1111/j.1572 0241.2003.07542.x, indexed in Pubmed: 12873581.

15. Drossman DA, Hasler WL. Rome IV-Functional GI Disorders: Disorders of Gut-Brain Interaction. Gastroenterology. 2016; 150(6): 1257-1261, doi:10.1053/j.gastro.2016.03.035, indexed in Pubmed: 27147121.

16. Neal KR, Hebden J, Spiller R. Prevalence of gastrointestinal symptoms six months after bacterial gastroenteritis and risk factors for development of the irritable bowel syndrome: postal survey of patients. BMJ. 1997; 314(7083): 779-782, indexed in Pubmed: 9080994.

17. Borgaonkar MR, Ford DC, Marshall JK, et al. The incidence of irritable bowel syndrome among community subjects with previous acute enteric infection. Dig Dis Sci. 2006; 51(5): 1026-1032, doi: 10.1007/ s10620-006-9348-1, indexed in Pubmed: 16758307.

18. Nair P, Okhuysen PC, Jiang ZD, et al. Persistent abdominal symptoms in US adults after short-term stay in Mexico. J Travel Med. 2014; 21(3): 153-158, doi: 10.1111/jtm.12114, indexed in Pubmed: 24621006.

19. Spiller R, Lam C. An update on post-infectious irritable bowel syndrome: role of genetics, immune activation, serotonin and altered microbiome. J Neurogastroenterol Motil. 2012; 18(3): 258-268, doi: 10.5056/jnm.2012.18.3.258, indexed in Pubmed: 22837873.

20. Parry SD, Barton JR, Welfare MR. Factors associated with the development of post-infectious functional gastrointestinal diseases: does smoking play a role? Eur J Gastroenterol Hepatol. 2005; 17(10): 1071-1075, indexed in Pubmed: 16148552.

21. Taylor DN, Houston R, Shlim DR, et al. Etiology of diarrhea among travelers and foreign residents in Nepal. JAMA. 1988; 260(9): 1245-1248, indexed in Pubmed: 3404637.

22. Dunlop SP, Jenkins D, Neal KR, et al. Relative importance of enterochromaffin cell hyperplasia, anxiety, and depression in postinfectious IBS. Gastroenterology. 2003; 125(6): 1651-1659, indexed in Pubmed: 14724817.

23. Gwee KA, Leong YL, Graham C, et al. The role of psychological and biological factors in postinfective gut dysfunction. Gut. 1999; 44(3): 400-406, indexed in Pubmed: 10026328.

24. Okhuysen PC, Jiang ZD, Carlin L, et al. Post-diarrhea chronic intestinal symptoms and irritable bowel syndrome in North American travelers to Mexico. Am J Gastroenterol. 2004; 99(9): 1774-1778, doi: 10.1111/j.1572-0241.2004.30435.x, indexed in Pubmed: 15330917.

25. Thornley JP, Jenkins D, Neal K, et al. Relationship of Campylobacter toxigenicity in vitro to the development of postinfectious irritable bowel syndrome. J Infect Dis. 2001; 184(5): 606-609, doi: 10.1086/322845, indexed in Pubmed: 11474430.

26. Spiller RC. Infection as a cause of irritable bowel syndrome. Hosp Med. 2003; 64(5): 270-274, indexed in Pubmed: 12789735.

27. Guilarte M, Santos J, de Torres I, et al. Diarrhoea-predominant IBS patients show mast cell activation and hyperplasia in the jejunum. Gut. 2007; 56(2): 203-209, doi: 10.1136/gut.2006.100594, indexed in Pubmed: 17005763.
28. Lee KJ, Kim YB, Kim JH, et al. The alteration of enterochromaffin cell, mast cell, and lamina propria T lymphocyte numbers in irritable bowel syndrome and its relationship with psychological factors. J Gastroenterol Hepatol. 2008; 23(11): 1689-1694, doi: 10.1111/j.14401746.2008.05574.x, indexed in Pubmed: 19120860.

29. Barbara G, Stanghellini V, De Giorgio R, et al. Activated mast cells in proximity to colonic nerves correlate with abdominal pain in irritable bowel syndrome. Gastroenterology. 2004; 126(3): 693-702, indexed in Pubmed: 14988823.

30. Barbara G, Wang B, Stanghellini V, et al. Mast cell-dependent excitation of visceral-nociceptive sensory neurons in irritable bowel syndrome. Gastroenterology. 2007; 132(1): 26-37, doi: 10.1053/j. gastro.2006.11.039, indexed in Pubmed: 17241857.

31. Dinan TG, Clarke G, Quigley EMM, et al. Enhanced cholinergic-mediated increase in the pro-inflammatory cytokine IL-6 in irritable bowel syndrome: role of muscarinic receptors. Am J Gastroenterol. 2008; 103(10): 2570-2576, doi: 10.1111/j.1572-0241.2008.01871.x, indexed in Pubmed: 18785949.

32. Dunlop SP, Jenkins D, Neal KR, et al. Randomized, double-blind, placebo-controlled trial of prednisolone in post-infectious irritable bowel syndrome. Aliment Pharmacol Ther. 2003; 18(1): 77-84, doi: 10.1046/j.1365-2036.2003.01640.x.

33. Hungin APS, Chang L, Locke GR, et al. Irritable bowel syndrome in the United States: prevalence, symptom patterns and impact. Aliment Pharmacol Ther. 2005; 21(11): 1365-1375, doi: 10.1111/j.13652036.2005.02463.x, indexed in Pubmed: 15932367.

34. Couturier E, Guillemin F, Mura M, et al. Impaired quality of life after chikungunya virus infection: a 2-year follow-up study. Rheumatology (Oxford). 2012; 51(7): 1315-1322, doi: 10.1093/rheumatology/ kes015, indexed in Pubmed: 22427407.

35. Javelle E, Ribera A, Degasne I, et al. Specific management of post-chikungunya rheumatic disorders: a retrospective study of 159 cases in Reunion Island from 2006-2012. PLoS Negl Trop Dis. 2015; 9(3): e0003603, doi: 10.1371/journal.pntd.0003603, indexed in Pubmed: 25760632.

36. Rodriguez-Morales AJ, Gil-Restrepo AF, Ramírez-Jaramillo V, et al. Post-chikungunya chronic inflammatory rheumatism: results from a retrospective follow-up study of 283 adult and child cases in La Virginia, Risaralda, Colombia. F1000Res. 2016; 5: 360, doi: 10.12688/ f1000research.8235.2, indexed in Pubmed: 27081477.

37. Zeana C, Kelly P, Heredia W, et al. Post-chikungunya rheumatic disorders in travelers after return from the Caribbean. Travel Med Infect Dis. 2016; 14(1): 21-25, doi: 10.1016/j.tmaid.2016.01.009, indexed in Pubmed: 26872414.

38. Brighton SW, Simson IW. A destructive arthropathy following Chikungunya virus arthritis - a possible association. Clin Rheumatol. 1984; 3(2): 253-258, doi: 10.1007/bf02030766.

39. Bouquillard E, Combe B. A report of 21 cases of rheumatoid arthritis following Chikungunya fever. A mean follow-up of two years. Joint Bone Spine. 2009; 76(6): 654-657, doi: 10.1016/j. jbspin.2009.08.005, indexed in Pubmed: 19945329.

40. Mathew AJ, Goyal V, George E, et al. Rheumatic-musculoskeletal pain and disorders in a na ve group of individuals 15 months following a Chikungunya viral epidemic in south India: a population based observational study. Int J Clin Pract. 2011; 65(12): 1306-1312, doi: 10.1111/j.1742-1241.2011.02792.x, indexed in Pubmed: 22093538.

41. Ribéra A, Degasne I, Jaffar Bandjee MC, et al. [Chronic rheumatic manifestations following chikungunya virus infection: clinical description and therapeutic considerations]. Med Trop (Mars). 2012; 72 Spec No: 83-85, indexed in Pubmed: 22693935. 
42. Renault P, Solet JL, Sissoko D, et al. A major epidemic of chikungunya virus infection on Reunion Island, France, 2005-2006. Am J Trop Med Hyg. 2007; 77(4): 727-731, indexed in Pubmed: 17978079.

43. Assunção-Miranda I, Cruz-Oliveira C, Da Poian AT. Molecular mechanisms involved in the pathogenesis of alphavirus-induced arthritis. Biomed Res Int. 2013; 2013: 973516, doi: 10.1155/2013/973516, indexed in Pubmed: 24069610.

44. Foissac M, Javelle E, Ray S, et al. Post-Chikungunya rheumatoid arthritis, Saint Martin. Emerg Infect Dis. 2015; 21(3): 530-532, doi:10.3201/eid2103.141397, indexed in Pubmed: 25695499.

45. Weaver SC, Lecuit M. Chikungunya virus and the global spread of a mosquito-borne disease. N Engl J Med. 2015; 372(13): 1231-1239, doi:10.1056/NEJMra1406035, indexed in Pubmed: 25806915.

46. Guo C, Zhou Z, Wen Z, et al. Global Epidemiology of Dengue Outbreaks in 1990-2015: A Systematic Review and Meta-Analysis. Front Cell Infect Microbiol. 2017; 7: 317, doi: 10.3389/ fcimb.2017.00317, indexed in Pubmed: 28748176.

47. Seet RCS, Quek AML, Lim ECH. Post-infectious fatigue syndrome in dengue infection. J Clin Virol. 2007; 38(1): 1-6, doi: 10.1016/j. jcv.2006.10.011, indexed in Pubmed: 17137834.

48. García G, González N, Pérez AB, et al. Long-term persistence of clinical symptoms in dengue-infected persons and its association with immunological disorders. Int J Infect Dis. 2011; 15(1): e38-e43, doi: 10.1016/j.jij.2010.09.008, indexed in Pubmed: 21112804.

49. Halstead SB. Observations related to pathogensis of dengue hemorrhagic fever. VI. Hypotheses and discussion. Yale J Biol Med. 1970; 42(5): 350-362, indexed in Pubmed: 5419208.

50. van de Velde NC, Mottram PL, Hogarth PM. FcgammaRII and multi-system autoimmune disease. Springer Semin Immunopathol. 2006; 28(4): 329-338, doi: 10.1007/s00281-006-0056-x, indexed in Pubmed: 17091247.

51. Lei HY, Yeh TM, Liu HS, et al. Immunopathogenesis of dengue virus infection. J Biomed Sci. 2001; 8(5): 377-388, doi: 10.1159/000054058, indexed in Pubmed: 11549879.

52. Sjöwall C, Wetterö J. Pathogenic implications for autoantibodies against C-reactive protein and other acute phase proteins. Clin Chim Acta. 2007; 378(1-2): 13-23, doi: 10.1016/j.cca.2006.12.002, indexed in Pubmed: 17239838.
53. Nanda SK, Jayalakshmi S, Mohandas S. Pediatric ischemic stroke due to dengue vasculitis. Pediatr Neurol. 2014; 51(4): 570-572, doi:10.1016/j.pediatrneurol.2014.06.019, indexed in Pubmed: 25266622.

54. Yoganathan S, Sudhakar SV, Priyambada L, et al. Stroke in a child with dengue encephalopathy. Ann Indian Acad Neurol. 2017; 20(3): 329-331, doi:10.4103/aian.AIAN_504_16, indexed in Pubmed: 28904475.

55. Bopeththa BV, Ralapanawa U. Post encephalitic parkinsonism following dengue viral infection. BMC Res Notes. 2017; 10(1): 655, doi: 10.1186/s13104-017-2954-5, indexed in Pubmed: 29187231.

56. Lana-Peixoto MA, Pedrosa D, Talim N, et al. Myelitis and cauda equina involvement following dengue fever. A case report and review of the literature. Mult Scler Relat Disord. 2018; 20: 48-50, doi: 10.1016/j. msard.2017.12.013, indexed in Pubmed: 29294422.

57. Puccioni-Sohler M, Ornelas AMM, de Souza AS, et al. First report of persistent dengue-1-associated autoimmune neurological disturbance: neuromyelitis optica spectrum disorder. J Neurovirol. 2017; 23(5): 768-771, doi: 10.1007/s13365-017-0555-7, indexed in Pubmed: 28748449.

58. Lana-Peixoto MA, Pedrosa D, Talim N, et al. Neuromyelitis optica spectrum disorder associated with dengue virus infection. J Neuroimmunol. 2018; 318: 53-55, doi: 10.1016/j.jneuroim.2018.02.003, indexed in Pubmed: 29475624.

59. Kamoi K, Mochizuki M, Ohno-Matsui K. Dengue fever-associated necrotizing scleritis: A case report with long-term follow-up. Medicine (Baltimore). 2018; 97(32): e11875, doi: 10.1097/ MD.0000000000011875, indexed in Pubmed: 30095666.

60. Kamath SJ, Nayak MK, Gour R, et al. Dengue stings the eye! J Clin Diagn Res. 2017; 11(9): ND03-ND05, doi: 10.7860/ JCDR/2017/25563.10610, indexed in Pubmed: 29207746.

61. Fang PP, Pfau M, Holz FG, et al. Persistent visual loss in dengue fever due to outer retinal damage. Clin Exp Ophthalmol. 2017; 45(7): 747-749, doi:10.1111/ceo.12960, indexed in Pubmed: 28414860.

62. Levaggi ND, Lucas AN, Barletta JÁ. Bilateral acute angle closure in a patient with dengue fever: a case report. Arq Bras Oftalmol. 2017; 80(4): 266-267, doi: 10.5935/0004-2749.20170065, indexed in Pubmed: 28954031. 